\title{
Did Covid-19 pandemic narrow the spectrum of surgical indications?
}

\author{
Ahmet Keskin ${ }^{1}$, Bulent Karslioglu ${ }^{1 *}$ \\ ${ }^{1}$ HSU PROF. CEMIL TASCIOGLU CITY HOSPITAL DEPARTMENT OF ORTHOPEDICS AND TRAUMATOLOGY, ISTANBUL, TURKEY
}

\begin{abstract}
Introduction. The Covid-19 outbreak has changed orthopedic practices more than expected. We are going through a period in which conservative treatment will become prominent when deciding on fractures with indistinct surgical margins in guidelines. Considering global tendency for surgical interventions in the pre-pandemic period, we tried to find out the answer to the following question: will conservative treatment be the shining star in the post pandemic period? Materials and Methods. 262 patients who were with "gray zone fractures-injuries" like extraarticular distal radius fracture, proximal humerus fracture and Weber type B ankle fracture was treated conservatively during March and August, 2020. Open or pathological fracture, fractures with vascular or neurological injury and fractures involving the articular joint were excluded. Results. 59 patients with proximal humerus fracture followed with arm-sling. Mean ASES scores at 6th was 48.3 and 69.912 th week. 91 patients with Weber B-type ankle fracture were followed up with below-knee plaster for 6 weeks. American Orthopedic Foot \& Ankle Score was 48 in the 6th week and 75 in the 12th week. 90 patients with distal radius fracture were followed up with plaster. Malunion was detected at 5 patients. Mean Quick Dash score at 6th weeks was 52.3 and 29.5 at 12 th weeks. Mean wrist flexion was 450 , wrist extension was 350 , forearm supination 600 and forearm pronation was 700 at final control. Conclusions. The conservative treatment experiences we have gained from pandemic periods probably will change our treatment algorithm.
\end{abstract}

Category: Original Research Paper

Received: January 14, 2021

Accepted: March 16, 2021

Published: May 10, 2021

\section{Keywords:}

Covid-19, fracture, distal radius, proximal humerus, ankle fracture

* Corresponding author:

Bulent Karslioglu,

HSU Prof. Cemil Tascioglu City Hospital Department of Orthopedics and Traumatology, Darulaceze Street No.25, Sisli, Istanbul, Turkey

E-mail: bukars@gmail.com

\section{Introduction}

In December 2019, pneumonia cases with unknown cause increased in Wuhan of Hubei Province, China [1]. The epidemic began to spread slowly as the local authorities failed to control the epidemic. The epidemic, in which the new coronavirus was identified as the cause, was named as 2019-nCoV. World Health Organization (WHO) later named it as coronavirus disease 2019 (Covid-19) [2]. On March 11, 2020, WHO described the outbreak as a worldwide pandemic. Nearly 33 million people in 215 countries have been diagnosed with Covid-19 and 995.000 of them died as of the writing of this article. Covid-19 has quickly become a global threat and proper hygiene, quarantine, social distancing, self-isolation has become the basic rules we must follow.

Covid-19's highly contagious feature, transmission by droplet, contact and air, and being infectious even without specific symptoms during the incubation period led to rethinking fracture treatment protocols [3,4]. It has been shown that there can be a transmission from patients to surgeons, as well as from surgeons to patients. Covid-19 infection may also develop in some patients after surgical treatment, as orthopedic surgeries tend to produce more aerosols and droplets due to the use of high-speed operating devices [5].

Tendency for conservative management began for "non-obligatory" fractures, to be able to protect patients, medical staff and other healthcare providers, and also the families and neighbors of exposed healthcare providers. Ministry of health recommended suspending elective procedures and outpatient visits, to reduce the burden on the health system, but not necessarily by using limited resources and personnel due to the high prevalence of Covid-19. In this period, orthopedic surgeons, like other doctors, took a position to fight at the front line to assist in emergency rooms and intensive care units.

Announcement of lock-down for people less than 20 years of age who might be asymptomatic but have high risk of transmitting disease, and people over 65 years of age 
who have high risk of mortality decreased the number of fractured patients admitted to the emergency department in our country. Therefore, fracture management was limited to those who had to go work due to the economic reasons, and also other persons who fall at home despite all precautions.

In our article, we tried to reveal the fracture management we applied to patients who were admitted to our hospital for approximately 6 months, from the date of March 11th when pandemic was announced to August 11th. Considering global tendency for surgical interventions in the prepandemic period, we tried to find the answer to the following question: will conservative treatment be the shining star to till post pandemic period?

\section{Materials and Methods}

Patients who were admitted to our emergency orthopedics department between March 11, 2020 and August 11, 2020 were evaluated retrospectively. 3210 patients were diagnosed with fractures within this period. Open or pathological fracture, fractures with an associated vascular or neurological injury, hip fracture, unstable pelvic fractures and articular or peri-articular fractures were considered as "obligatory fractures to surgically treat". 1290 patients who met these criteria were treated surgically. 1680 of the remaining patients were treated conservatively. Patients who did not want to be operated due to Covid-19 infection fear, the fractures in which surgical and conservative treatment boundaries are intertwined and which also could be treated conservatively according to guidelines were called as "gray zone fractures". 240 patients who met the inclusion criteria were included in the study (Figure 1). Diagnosis was based on radiograph or CT scan views. The patients were informed about the risk for Covid19 infection and also non-union and possible restricted joint movement if conservative treatment was chosen. Conservative treatment decisions were made according to radiological appearance of fractures, medical conditions and expectations of the patients.
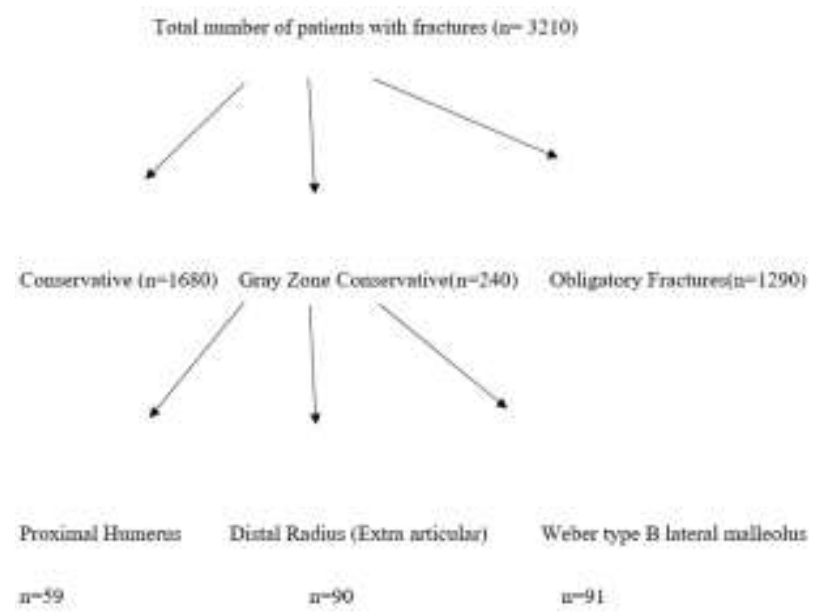

Figure 1. Distribution of patients included in the study
Three control groups were formed retrospectively, with the same age and fracture type in order not to cause bias. For this purpose, patients who were treated surgically between June 2019 and January 2020 with an adequate follow-up period were selected. The medical records of the patients were checked for clinical scores and eligible patients were included in the study. All participants were informed and informed consent form was obtained. Study was approved by our Institutional Review Board (14/07/2020-312).

Patients with extraarticular distal radius fracture (EADRF) were followed with plaster for 6 weeks. Quick dash scoring was done to all patients at $6^{\text {th }}$ and $12^{\text {th }}$ week. Patients with proximal humerus fractures (PHF) followed with abduction supported shoulder arm sling for 6 weeks. American shoulder and Elbow Surgeons (ASES) scoring was done at final control and at $6^{\text {th }}$ and $12^{\text {th }}$ week. Patients with Arbeitsgemeinschaft Osteosynthesefragen (AO) Weber B-type ankle fracture were followed up with belowknee plaster for 6 weeks and American Orthopedic Foot \& Ankle Score (AOFAS) was applied after plaster removal $\left(6^{\text {th }}\right.$ week $)$ and $12^{\text {th }}$ week.

Table 1. The mean age and follow-up time of all patients

\begin{tabular}{|l|c|c|}
\hline & $\begin{array}{c}\text { Mean Age } \\
\text { (years) }\end{array}$ & $\begin{array}{c}\text { Mean Follow- } \\
\text { up (days) }\end{array}$ \\
\hline Prox. Humerus & $70(48-83)$ & $71(58-92)$ \\
\hline $\begin{array}{l}\text { Distal Radius (Extra- } \\
\text { articular) }\end{array}$ & $68.2(58-76)$ & $59(45-96)$ \\
\hline $\begin{array}{l}\text { Weber type B lateral } \\
\text { malleolus }\end{array}$ & $52(28-67)$ & $65(48-93)$ \\
\hline
\end{tabular}

\section{Results}

The mean age and follow-up time of all patients included in the study can be seen in Table 1. According to Neer's classification, 48 of 59 PHF patients were 2-part surgical neck fractures, 10 were 3-part, 1 were 4-part fractures. In the control group, 26 patients were 2-part surgical neck fractures, 25 patients were 3-part, 3 were 4part fractures according to Neer's classification. The mean age of the patients was 70 (48-83) years. The patients were followed with abduction supported shoulder arm sling for 6 weeks. All patients were called for control at $3^{\text {rd }}$ week and a Xray's were taken. Patients were recommended to do elbow and wrist exercises. On the $6^{\text {th }}$ week control, a radiograph was taken and the arm sling was removed and patients were directed to physical therapy for shoulder exercises (Figure 2). ASES scoring was performed for all patients at $6^{\text {th }}$ week during the control examination and at $12^{\text {th }}$ week by telephone to prevent patients from coming to the hospital and becoming infected. Mean ASES scores at 6 weeks was 48,3 and 69,9 at $12^{\text {th }}$ week. Surgical planning 
was performed for elective reverse shoulder arthroplasty in 5 patients at the latest follow-up. Although there was no statistically significant difference between the ASES scores 8 patients were planned for reverse shoulder replacement surgery in control group.

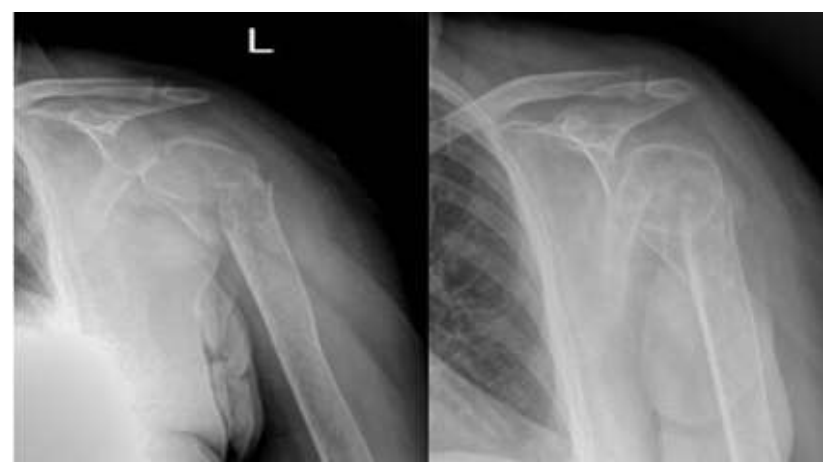

Figure 2. Patients were directed to physical therapy for shoulder exercises after 6th week control.

91 patients with AO Weber B-type ankle fracture were followed up with below-knee plaster for 6 weeks. Partial weight-bearing was allowed after $3^{\text {rd }}$ week. $\mathrm{X}$ rays were taken (Figure 3 ) and the plaster was removed at $6^{\text {th }}$ week. Bone union was observed in all patients and they were encouraged to walk with full weightbearing. AOFAS scores was applied to the patients at $6^{\text {th }}$ and $12^{\text {th }}$ week. The score was 48 in the $6^{\text {th }}$ week and 75 in the $12^{\text {th }}$ week. 60 patients were determined retrospectively for the control group. Open reduction and internal fixation were applied to all patients. Full weightbearing was allowed 1 month after the operation. AOFAS scores were 85 at $12^{\text {th }}$ week control and was statistically significant $(p<0,05)$. The better AOFAS scores in the control group may be due to the less pain in the 12th week after surgery.

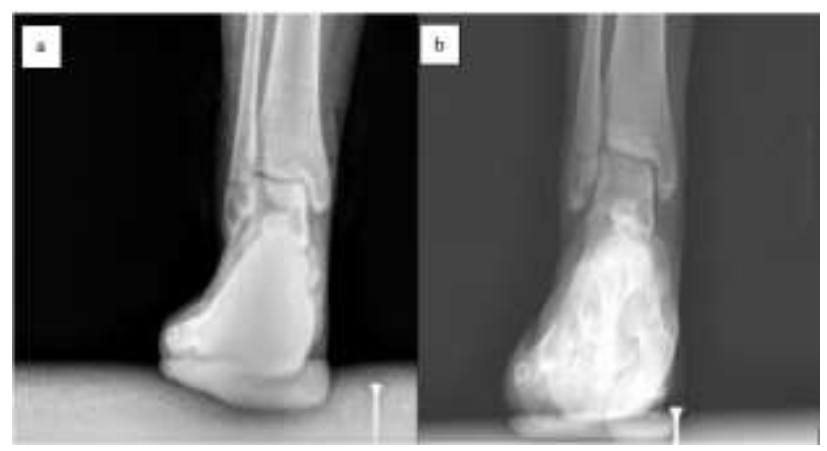

Figure 3. Radiological views before (a), and 6 weeks after plaster removal (b)

93 patients with EADRF were followed up with aboveelbow plaster for 3 weeks and below-elbow plaster for the following 3 weeks (Figures 4-5). Nonunion was not detected, but malunion was detected in 5 patients. 3 of them were low-demand $>75$ years old patients. Distal radius osteotomy was planned for 2 of 5 patients. Mean Quick Dash score at $6^{\text {th }}$ weeks was 52.3 and 29.5 at $12^{\text {th }}$ weeks. Mean wrist flexion was $45^{\circ}$, wrist hyperextension was $35^{\circ}$, ulnar deviation was $25^{\circ}$, radial deviation was $10^{\circ} .110$ patients treated surgically for AEDRF were included in retrospectively as a control group. All patients were surgically treated with open reduction and internal fixation. $12^{\text {th }}$ week Quick Dash Scores were mean wrist flexion was $55^{\circ}$, wrist extension was $50^{\circ}$, ulnar deviation was $25^{\circ}$, radial deviation was $20^{\circ}$.
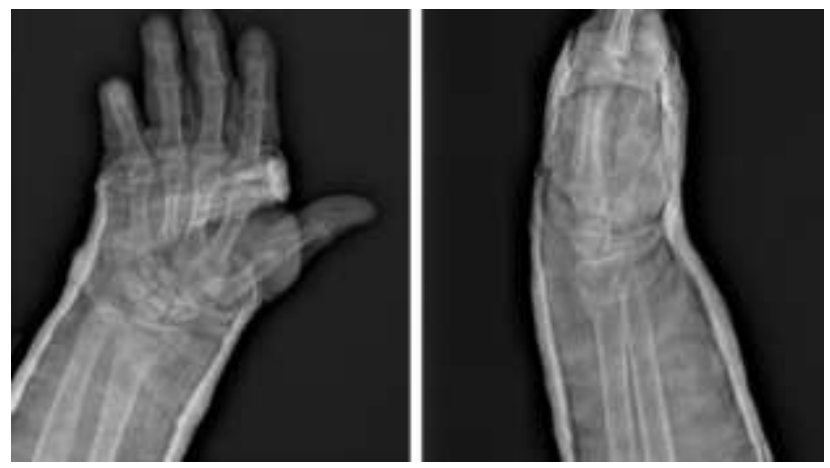

Figure 4. Patients were followed up with above-elbow plaster for 3 weeks and below-elbow plaster for the following 3 weeks

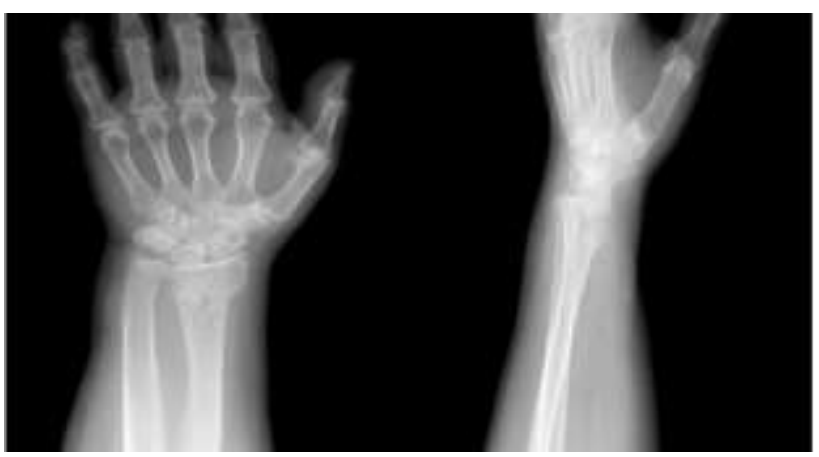

Figure 5. X-rays were taken after 6 weeks of plaster treatment.

\section{Discussions}

Covid 19, which started to be a big problem for the whole world after March 2020, began to change the surgical trends. Covid-19's highly contagious feature, transmission by droplet, contact and air, and being infectious even without specific symptoms during the incubation period and susceptibility to pulmonary infection in patients especially with lower-limb fracture are major concerns in the treatment of fracture patients [5]. The simplest rule to prevent contamination is to avoid exposure to the virus. Virus exposure can be prevented by reducing aerosol generating procedures (AGP) and using personal protective equipment (PPE). Orthopedic surgeries tend to produce more aerosols and droplets due to the use of highspeed operating devices [6]. Considering that the percentage of orthopedic surgeons infected with Covid 19 in 8 hospitals in Wuhan was close to $20 \%$, patient selection for surgery could become a more important issue [7]. In order to ensure the correct use of limited resources, we had to apply conservative treatment to the cases we used before to perform surgery according to the wishes of the patients 
(we named as gray-zone fractures). Exceptions were open or pathological fractures, fractures with an associated vascular or neurological injury, unstable pelvic fractures and articular and peri-articular fractures, so fractures for which operative management may be required at a later stage.

Postponing a surgery for more than 4-6 weeks may cause to patient more harm than good in the future, and may lead to limitation at affected extremity movement, malunion or even nonunion. However, during the pandemic period, the priority should be to prevent mortality due to Covid-19. It should be discussed with the patient that Covid-19 infection may develop in the perioperative period [8]. There are publications suggesting that increased surgical stress and decreased body resistance in the postoperative period may activate or aggravate the progression and mortality of COVID-19 [9]. The decision for the operation must therefore be made by consensus, but guided by the surgeon.

Satisfactory results can be obtained especially in conservatively treated upper extremity fractures. Studies have shown that, with the exception of open fractures and pathological fractures, there were no statistically or clinically significant differences between the results of operative and non-operative treatment in adults with a displaced proximal humerus fracture [10-12]. The Neer's criteria of displacement is constantly revised for surgical indication.

The treatment of displaced three and four-part fractures is still controversial, and parameters like the general condition of the patient (e.g., comorbidity, expectations), 'personality` of the fracture (e.g., open, with osteoporosis), and the surgeon-related aspects (e.g., experience) are the most important for surgical decision [12]. Humeral head perfusion is another important parameter for surgical decision. Radiologically developed criteria, which are called as Hertel criteria, provide valuable information about the vascularity of the humeral head [13].

Shoulder fractures that must be mandatory treated are open or pathological fractures, an associated vascular or neurological injury, head-splitting fracture, a severe ipsilateral injury to the shoulder girdle aka 'floating shoulder [14]. Patients who complied with our conservative treatment indications (excepting obligatory fractures and patients whose humeral head perfusion was preserved according to radiological evaluations), whose medical condition were not suitable for surgery, who didn't want to be operated due to fear of Covid-19 were treated with sling immobilization.

Patients were encouraged to do elbow and wrist exercises at $3^{\text {rd }}$ weeks. Patients were directed to intensive physical therapy movements to do at home after radiological bone healing was detected at $1^{\text {st }}$ month followup (Figure 2). Patients were advised not to do overhead movements in the early period, but to do any movements that can continue their social life. Although 59 patients diagnosed with PHF were also candidates for surgery, surgery was planned for only $8 \%$ of patients after conservative treatment. The ASES scores showing that the patients had a good social life adaptation may be the consequence of their compliance to conservative treatment and physical therapy afterwards. There was no significant difference between ASES scores compared to the control group. The higher number of candidates for shoulder arthroplasty may be due to the selection of more complicated fractures for surgery.

Weber type B fractures are the most common ankle fractures [15]. Those who recommend surgery for minimally displaced weber type B fractures suggest that they can only eliminate further displacement and instability with surgery. In addition, there are surgeons who state that surgical results are not clinically superior to below-knee plaster treatment. However, they also draw attention to the risks associated with surgery and anesthesia, the risk of revision surgery, the risk of infection, and the cost [16]. Studies have revealed that surgical and non-surgical treatments are not superior to each other for this type of fracture $[16,17]$. During the pandemic, we conservatively treated Weber Type B fractures (another gray area fractures), which we had previously tended to perform surgery on. Although we have a short follow-up period, we found that patients can slowly return to their social lives by the help of good physical therapy, even though their pain continues. Investigation of the presence of osteoarthritis in these patients can provide information about long-term results.

Extraarticular distal radius fractures in elderly low demanded patients were other fractures we treated with closed reduction and above elbow plaster cast immobilization for 6 weeks (Figure 4-5). Restoration of normal radiological parameters might be important for younger patients but not for patients older than $>60$ years $[18,19]$. Studies have revealed that radiological outcomes are not related to functional outcomes in the assessment after 24 months [19-21]. After 6 weeks of plaster treatment, bony union was observed and patients were offered a physical therapy program that they could do at home. Nonunion was not detected, but malunion was detected in 5 patients. 3 of them were low-demand $>75$ years old patients.

2 patients (2.2\% of all distal radius fracturs) were scheduled to undergo osteotomy due to malunion. The lack of significant difference between Quick Dash Scores and wrist range of motion (ROM) measurements compared to the control group may be due to the relatively young age (mostly under 70) of the patients in both groups. The younger age of the patients than the general EADR population is due to the restriction of the elderly patients from going out to the streets due to lock down. We need a time to evaluate long-term functional results. 


\section{Conclusions}

The Covid-19 outbreak changed orthopedic practices more than we thought. Our desire for surgery was replaced by conservative treatment in order to protect patients and medical staff. First wave of COVID- 19 pandemic, most likely will be followed by a second and/or third wave of infections if an effective vaccine is not found. It is very clear that the conservative treatment experiences we have gained from pandemic periods will change our treatment algorithm, unless it is overshadowed by our ambition to perform surgery for different reasons. We are going through a period in which conservative treatment will become prominent when deciding on fractures with indistinct surgical margins in guidelines.

\section{Conflict of interest disclosure}

There are no known conflicts of interest in the publication of this article. All authors, their immediate family, and any research foundation with which they are affiliated did not receive any financial payments or other benefits from any commercial entity related to the subject of this article. The manuscript was read and approved by all authors.

\section{Compliance with ethical standards}

Any aspect of the work covered in this manuscript has been conducted with the ethical approval of all relevant bodies and that such approvals are acknowledged within the manuscript. Each author certifies that his or her institution has approved the reporting of this report, that all investigations were conducted in conformity with ethical principles of research. All participants were informed and written informed consent form was obtained. Study was approved by our Institutional Review Board (14/07/2020312)

\section{References}

1. Huang C, Wang Y, Li X, Ren L, Zhao J, Hu Y, Zhang L, Fan G, Xu J, Gu X, Cheng Z, Yu T, Xia J, Wei Y, Wu W, Xie X, Yin W, Li H, Liu M, Xiao Y, Gao H, Guo L, Xie J, Wang G, Jiang R, Gao Z, Jin Q, Wang J, Cao B. Clinical features of patients infected with 2019 novel coronavirus in Wuhan, China. Lancet. 2020;395(10223):497-506. doi: 10.1016/S01406736(20)30183-5

2. Zhu N, Zhang D, Wang W, Li X, Yang B, Song J, Zhao X, Huang B, Shi W, Lu R, Niu P, Zhan F, Ma X, Wang D, Xu W, Wu G, Gao GF, Tan W; China Novel Coronavirus Investigating and Research Team. A Novel Coronavirus from Patients with Pneumonia in China, 2019. N Engl J Med. 2020;382(8):727-733. doi: 10.1056/NEJMoa2001017
3. Holshue ML, DeBolt C, Lindquist S, Lofy KH, Wiesman J, Bruce H, Spitters C, Ericson K, Wilkerson S, Tural A, Diaz G, Cohn A, Fox L, Patel A, Gerber SI, Kim L, Tong S, Lu X, Lindstrom S, Pallansch MA, Weldon WC, Biggs HM, Uyeki TM, Pillai SK; Washington State 2019-nCoV Case Investigation Team. First Case of 2019 Novel Coronavirus in the United States. N Engl J Med. 2020;382(10):929-936. doi: 10.1056/NEJMoa2001191

4. Khan RN, Khan AI, Loya A, Parvaiz MA. Modifying Surgical Practice in the Times of Current COVID-19 Pandemic. J Coll Physicians Surg Pak. 2020;30(10):121123. doi: 10.29271/jcpsp.2020.supp2.121

5. Chen YC, Lin WC. Risk of long-term infection-related death in clinical osteoporotic vertebral fractures: A hospitalbased analysis. PLoS One. 2017;12(8):e0182614. doi: 10.1371/journal.pone.0182614

6. Mi B, Xiong Y, Lin Z, Panayi AC, Chen L, Liu G. COVID-19 Orthopaedic Safe Care Toolset: Guidelines for the Diagnosis and Management of Patients with Fracture and COVID-19. J Bone Joint Surg Am. 2020;102(13):1116-1122. doi: 10.2106/JBJS.20.00532

7. Guo X, Wang J, Hu D, Wu L, Gu L, Wang Y, Zhao J, Zeng L, Zhang J, Wu Y. Survey of COVID-19 Disease Among Orthopaedic Surgeons in Wuhan, People's Republic of China. J Bone Joint Surg Am. 2020; 102(10):847-854. doi: 10.2106/JBJS.20.00417

8. Saxena A, Bullock M, Danoff JR, Rodd DS, Fischer SJ, Stronach BM, Levine BR. Educating Surgeons to Educate Patients About the COVID-19 Pandemic. J Arthroplasty. 2020;35(7S):S65-S67. doi: 10.1016/j.arth.2020.04.037

9. Lei S, Jiang F, Su W, Chen C, Chen J, Mei W, Zhan LY, Jia Y, Zhang L, Liu D, Xia ZY, Xia Z. Clinical characteristics and outcomes of patients undergoing surgeries during the incubation period of COVID-19 infection. EClinicalMedicine. 2020;21:100331. doi: 10.1016/j.eclinm.2020.100331

10. Handoll HH, Keding A, Corbacho B, Brealey SD, Hewitt C, Rangan A. Five-year follow-up results of the PROFHER trial comparing operative and nonoperative treatment of adults with a displaced fracture of the proximal humerus. Bone Joint J. 2017;99$\mathrm{B}(3): 383-392$. doi: 10.1302/0301-620X.99B3.BJJ2016-1028

11. Orman S, Mohamadi A, Serino J, Murphy J, Hanna P, Weaver MJ, Dyer G, Nazarian A, von Keudell A. Comparison of surgical and non-surgical treatments for 3- and 4-part proximal humerus fractures: A network meta-analysis. Shoulder Elbow. 2020;12(2):99-108. doi: 10.1177/1758573219831506

12. Maier D, Jaeger M, Izadpanah K, Strohm PC, Suedkamp NP. Proximal humeral fracture treatment in adults. J Bone Joint Surg Am. 2014;96(3):251-61. doi: 10.2106/JBJS.L.01293 
13. Hertel R, Hempfing A, Stiehler M, Leunig M. Predictors of humeral head ischemia after intracapsular fracture of the proximal humerus. J Shoulder Elbow Surg. 2004;13(4):427-33. doi: 10.1016/j.jse.2004.01.034

14. Murray IR, Amin AK, White TO, Robinson CM. Proximal humeral fractures: current concepts in classification, treatment and outcomes. J Bone Joint Surg Br. 2011;93(1):1-11. doi: 10.1302/0301620X.93B1.25702

15. Martin AG. Weber B ankle fracture: an unnecessary fracture clinic burden. Injury. 2004;35(8):805-8. doi: 10.1016/j.injury.2003.12.013

16. Mittal R, Harris IA, Adie S, Naylor JM; CROSSBAT Study Group. Surgery for Type B Ankle Fracture Treatment: a Combined Randomised and Observational Study (CROSSBAT). BMJ Open. 2017;7(3):e013298. doi: 10.1136/bmjopen-2016-013298

17. Van Schie-Van der Weert EM, Van Lieshout EM, De Vries MR, Van der Elst M, Schepers T. Determinants of outcome in operatively and non-operatively treated Weber-B ankle fractures. Arch Orthop Trauma Surg. 2012;132(2):257-63. doi: 10.1007/s00402-011-1397-z
18. Young BT, Rayan GM. Outcome following nonoperative treatment of displaced distal radius fractures in low-demand patients older than 60 years. J Hand Surg Am. 2000;25(1):19-28. doi: 10.1053/jhsu.2000.jhsu025a0019

19. Chang HC, Tay SC, Chan BK, Low CO. Conservative treatment of redisplaced Colles' fractures in elderly patients older than 60 years old - anatomical and functional outcome. Hand Surg. 2001;6(2):137-44. doi: $10.1142 / \mathrm{s} 0218810401000606$

20. Fujii K, Henmi T, Kanematsu Y, Mishiro T, Sakai T, Terai T. Fractures of the distal end of radius in elderly patients: a comparative study of anatomical and functional results. J Orthop Surg (Hong Kong). 2002; 10(1):9-15. doi: 10.1177/230949900201000103. PMID: 12401915.

21. Anzarut A, Johnson JA, Rowe BH, Lambert RG, Blitz S, Majumdar SR. Radiologic and patient-reported functional outcomes in an elderly cohort with conservatively treated distal radius fractures. J Hand Surg Am. 2004;29(6):11217. doi: $10.1016 /$ j.jhsa.2004.07.002 